\section{Executive Committee Decisions}

Exceptionally, the EPS Executive Committee held its June meeting in Eindhoven so that participants and those in a special meeting with the Presidents of member societies could ween Science and Technology' held to celebrate the 80th birthday of H.B.G. Casimir.

High on the agenda was the report from the Review Committee which has met three times since the Council meeting in Zagreb in March. In order that new initiatives can be better sustained, it recommends that we are more flexible in the length of time a President can serve, and to give the full Executive Committee more time to devote to EPS projects, an inner panel comprising the President, Vice-President, Secretary and Treasurer together with the Executive Secretary will be charged with handling the more routine problems. Such changes were accepted by the Executive Committee as well as those relating

\section{Restructuring the Advisory Committees}

Our Advisory Committees are being reorganised to take account of the project role that several of them now have as against their original advisory function, and are being renamed Action Committees. Members will be selected ad personam rather than by delegation and so should be better suited to the jobs in hand, as well as making for smaller and more dynamic bodies. They will be backed by a network of national and scientific correspondents while task forces for particular limited term actions are also envisaged. Programmes will be more carefully targetted to the needs and capabilities of EPS and will be less ad hoc than they have been at times in the past. Draft terms of reference have been drawn up and are being discussed with the Chairmen who are nominated by the Executive Committee. This is why in the Directory (page 105) only the Chairmen (and Secretaries) are cited; the full Committees will be published later. Note that a Financial Resources Committee is being formed and this will supersede the Finance Committee. Also the Scientific Freedom Committee has been dissolved, even though the concern about this subject more easily attend the seminar 'Betto the Advisory Committees. remains. Action will be taken by the Executive Committee in consultation with the most appropriate people, as and when the need arises.

\section{Uniting Europe's Physical Societies}

The most revolutionary proposal before the Executive Committee however was in the form of a recommendation signed by some 60 Individual Ordinary Members who had taken part in a general meeting of the members of the Atomic and Molecular Physics Division held at the Divisional Conference in Bordeaux (ECAMP-3) in April. This called for measures to be taken to make all members of EPS national societies automatically individual members of EPS with appropriate contributions being paid by the national societies. The motion was also placed before the meeting with the Presidents of the national societies where it gained considerable sympathy amongst particularly (but not exclusively) the smaller societies. Whilst it was concluded that there was no prospect of implementing such a fundamental change in the immediate future, the long-term objective of a single European Physical Society with national sections was a vision that should be in front of us. The practical problems posed by the many languages in Europe, the many currencies and non-convertibility, the differences in strength and legal standing of the various societies, the shear size of the task of serving some 40-50000 physicists as a unit, quite apart from breaking with established traditions ruled any immediate change out of court, but the idea has been launched and we can expect to see a progressive erosion of the barriers to be overcome. For the immediate, it was concluded that the balance laid down by the founders between society and individual membership was near the optimum although an extension of the payment scale for the very big societies (notably the German Physical Society and The Institute of Physics) beyond the present cut-off at 10000 was reasonable. This proposal which put to Council at its next meeting.

\section{8th General Conference of EPS}

Plans are well on course for the 8th General Conference of EPS, 'Trends in Physics', in Amsterdam according to the Chairman of the International Programme Committee, Hendrick de Waard. The first bulletin which includes a pre-registration form has been printed and is being given a wide circulation. Details of student grants will be published in September. Particular attention has been paid to applied topics in the programme and in the main these are being grouped in the first two days, for the convenience of industrial Associate Members who will be meeting just before the opening. Dates to retain are September 4-8, 1990. implies a change in the By-Laws will be

\section{ISTITUTO NAZIONALE DI FISICA NUCLEARE}

\author{
(I.N.F.N.)
}

Post-doctoral fellowships for non Italian citizens in the following research areas:

Theoretical Physics (n. 8) Experimental Physics (n. 14)

Applications are invited for one year fellowships, starting on April-May 1990.

The successful applicants may carry on their research at any of the following laboratories and sections of I.N.F.N.:

National Laboratories of Frascati (Rome)

National Laboratories of Legnaro (Padova)

National Southern Laboratories (Catania)

National Gran Sasso Laboratory (L'Aquila)

INFN Sections in the universities of: Turin, Milan, Padua, Genoa, Bologna, Pisa, Rome

"La Sapienza", Rome II, Naples, Catania, Trieste, Florence, Bari, Pavia, Perugia, Ferrara,

Cagliari, Lecce and National Institute for Health (Rome).

The annual gross salary is LIT 24000000, corresponding to LIT 1600000 net per month, plus travel expenses from home Institution to I.N.F.N. Section or Laboratory and return.

Deadline for application is December 31, 1989.

Candidates should submit an application form and a statement of their research interests, including three letters of reference.

For further information and application forms, please apply to:

Fellowship Service - Personnel Office, Istituto Nazionale di Fisica Nucleare (INFN)

Casella Postale 56 - 00044 Frascati (Roma) Italy. 